\title{
REVISÃO
}

\section{DIREITOS HUMANOS E O MEIO AMBIENTE}

\author{
Éder Clementino dos Santos ${ }^{1}$; Erlei Clementino dos Santos ${ }^{2}$; Cristiane de Freitas ${ }^{3}$
}

\author{
1Docente do IFSULDEMINAS - Campus de Inconfidentes-MG ederclementino@gmail.com - Bacharelando de \\ Direito da Unipinhal - Gestor Ambiental Empresarial \\ ${ }^{2}$ Pedagoga do IFSULDEMINAS - Campus de Machado-MG \\ ${ }^{3}$ Bacharelando do curso de Direito da Unipinhal
}

\section{RESUMO}

O direito fundamental ao meio ambiente tem sua dignidade fundamentada no direito à vida. Contudo, a sua consecução envolve além dos elementos jurídicos os fatores políticos, culturais, econômicos dentre outros. Estes devem ser levados em consideração quando do estabelecimento de políticas públicas, legislativas, exercício da cidadania etc. A eficácia de fazer valer o direito da pessoa humana deve ser entendida num contexto de crise do sistema jurídico, levantando-se algumas questões tais como a morosidade no julgamento dos processos, o acesso à justiça, o controle da magistratura, entre outros temas de destaque. A partir desta análise, podem ser destacadas algumas soluções práticas como a idéia das varas especializadas; e soluções teóricas oferecidas, pela teoria garantista; além da necessidade de uma mudança na cultura hermenêutica e jurisprudência, conferindo-se relevo a valores e princípios com o intuito de se aproximar a práxis jurídica à realidade social. Dessa forma, a defesa do meio ambiente ainda é um dos maiores problemas enfrentados pelos Estados e pela comunidade internacional, haja vista a sua estreita relação com o desenvolvimento. O que é preciso é que o meio ambiente seja visto e respeitado em estreita vinculação com os direitos humanos, já que inegáveis as relações de interdependência e complementaridade existentes entre o direito à vida e o direito ao meio ambiente ecologicamente equilibrado e sustentável de tal sorte que possa constituir um dos fatores determinantes da sua qualidade de vida da dignidade da pessoa humana.

Palavras-chave: Dignidade humana, meio ambiente, direitos humanos.

\section{HUMAN RIGHTS AND THE ENVIRONMENT}

\begin{abstract}
The fundamental right to the environment has its dignity based in the right to life. However, its achievement involves besides the juridical elements the political, cultural, economic factors among another. These should be carried in consideration when of the establishment of public, legislative political, citizenship exercise etc. The effectiveness of doing be worth person's human right should be understood in a crisis context of the juridical system, getting up some matters such as the slowness in the processes trial, the access to justice, the judicature control, among others highlight themes. To leave of this analysis, they can be highlighted some solutions practices as the idea of the specialized rods; And offered theoretical solutions, by the theory keep; Besides the need to a change in the culture hermeneutic and jurisprudence, checking itself
\end{abstract}


relief for values and principles with wish of if you approach for habit juridical to the social reality. Thus, the environment defense still is one of the largest problems faced by the State and by the international community, as shown by its narrow relation with the development. What is necessary is that the environment be seen and respected in narrow union with the human rights, since undeniable the interdependence relations and existing complementarity between right to life and the right to ecologically balanced and sustainable environment of such a luck that can constitute one of the determinate factors of its life quality of the human person.

Keys-word: Human dignity, environment, fundamental rights.

\section{INTRODUÇÃO}

Nos dias atuais, as preocupações com o meio ambiente adquiriram suprema importância nas últimas três décadas do século XX e a cada dia se apresenta ocupando um espaço cada vez mais relevante nas reflexões dos fóruns internacionais, nos meios de comunicação e nas inquietudes da sociedade civil em virtude ao perigo eminente de destruição da biosfera, afetada principalmente pela exploração descontrolada de recursos naturais. A pior crise é a dos recursos renováveis. Em todo o planeta, as espécies marinhas, terrestres e aéreas, as florestas tropicais e sua incomensurável reserva genética, a camada superior do solo, a água potável, etc., estão em um movimento acelerado de diminuição, já que a exploração é maior e mais veloz que a renovação. Esta crise acrescida da mudança climática e da destruição da atmosfera afeta a vida humana e de todos os seres vivos de forma alarmante e talvez irreversível.

As mudanças deste mundo contemporâneo que ocorrendo de forma rápida e com uma dimensão incalculável pode influir diretamente no gozo de direitos humanos, tais como o direito a vida e a saúde, direitos estes garantidos há muito tempo como direitos fundamentais do ser humano. Sendo assim, os seres humanos passam a ser o centro das preocupações com o ambiente equilibrado e sustentável, que por ora visa proporcionar direito a uma vida saudável e produtiva, em harmonia com a natureza.

É evidente que para muitos a proteção ambiental tem como objetivo garantir a manutenção ou a geração de condições necessárias a uma circunvizinhança ambiental saudável em si mesmo e ao desenvolvimento da espécie humana, no entanto, podemos argüir que o direito ao ambiente é direito humano por excelência, mesmo não estando reconhecido em nenhum instrumento jurídico internacional sobre direitos humanos. Mas, independentemente de qualquer instrumento jurídico, torna-se necessário ocorrer à verdadeira efetivação dos direitos humanos, do direito à vida em ambiente ecologicamente equilibrado e sustentável que hodiernamente, passa a representar a maior busca da humanidade.

Neste diapasão, a defesa do meio ambiente ainda é um dos maiores problemas enfrentados pelos Estados e pela comunidade internacional, haja vista a sua estreita relação com o desenvolvimento. O que é preciso é que o meio ambiente seja visto e respeitado em estreita vinculação com os direitos humanos, mediante inegáveis as relações de interdependência e complementaridade existentes entre o direito à vida e o direito ao meio ecologicamente equilibrado e sustentável.

\section{DIREITOS HUMANOS E FUNDAMEN- TAIS}

Num sentido próprio, em que se conceituem como "direitos humanos", quaisquer direitos atribuídos a seres humanos, como tais, pode ser assinalado o reconhecimento de tais direitos na Antiguidade: no Código de Hamurabi na Babilônia no século XVIII an- 
tes de Cristo, no pensamento de Amenófis IV no Egito no século XIV a. C, na filosofia de Mêncio na China. século IV a. C, na República de Platão na Grécia no século IV a. C, no Direito Romano e em inúmeras civilizações e culturas ancestrais (Comparato, 2001).

$\mathrm{Na}$ antiguidade não se conhecia o fenômeno da limitação do poder do Estado. As leis que organizavam os Estados não atribuíam ao indivíduo direitos frente ao poder estatal. Quando Aristóteles definiu "Constituição", tinha diante de si esse tipo de legislação (Alexy, 1997). Não obstante tenha sido Atenas o berço de relevante pensamento político. Não se imaginava então a possibilidade de um estatuto de direitos oponíveis ao próprio Estado. A formação da Pólis foi precedida da formação de um território cultural, como notou François de Polignae. Este balizou os limites da cidade grega (Comparato, 2001).

Sem garantia legal, os "direitos humanos" padeciam de certa precariedade na estrutura política. O respeito a eles ficava na dependência da virtude e da sabedoria dos governantes. Esta circunstância, porém, não exclui a importante contribuição de culturas antigas na criação da idéia de Direitos Humanos (Alexy, 1997).

É interessante observar que alguns autores pretendem afirmar que a história dos Direitos Humanos começou com o balizamento do poder do Estado pela lei. Creio que essa visão é errônea. Obscurece o legado de povos que não conheceram a técnica de limitação do poder, mas privilegiaram enormemente a pessoa humana nos seus costumes e instituições sociais.

$\mathrm{Na}$ sua origem, a palavra direito significa exatamente aquilo que é reto, correto ou justo. Daí a idéia de que um homem honesto é um homem "direito". Por outro lado, o termo "direito" se opõe ao que é torto, avesso ou injusto. Mediante isto, sempre podemos dizer: “isso não está direito!". No dia 8 de março de 1857 , por exemplo, na cidade norte-americana de Nova Iorque, operárias tecelãs fizeram uma greve, ocupando a fábrica de tecidos na qual trabalhavam. Reivindicavam melhores condições de trabalho e a equiparação de salários com os homens, que ganhavam três vezes mais pelo mesmo trabalho. A manifestação foi reprimida com uma brutal violência. As mulheres foram trancadas dentro da fábrica, que foi incendiada. Cerca de 130 tecelãs morreram carbonizadas. "O que podemos pensar sobre este ato bárbaro"? Nesse sentido, falar da luta pelos direitos humanos é, portanto, em primeiro lugar, falar do desejo e da necessidade que possuímos de viver em um mundo justo. Contudo, direitos não são apenas demandas por justiça. Eles são, também, os reconhecimentos de que algo nos é devido. Neste sentido, os direitos não são favores, súplicas ou gentilezas. Se existe um direito, é porque há um débito e uma obrigação correlata. Por conseguinte, não se pede um direito, luta-se por ele. Quando se reivindica por algo que seja devido, não se está rogando um favor, mas exigindo que justiça seja feita, que o direito seja reconhecido. $\mathrm{Na}$ verdade, é poder se ver como sujeito de direitos. Poder exigir que tais direitos sejam respeitados. Poder lutar para ter novos direitos. Eis uma transformação que afetou radicalmente a maneira como se pode perceber como pessoas e cidadãos. Isto é uma verdadeira revolução no ensejo ao direito (Venosa, 2010; Dallari, 2005).

No âmbito internacional, os direitos humanos são protegidos por meio do Direito internacional humanitário, relativo ao regime geral de proteção da pessoa em situação de conflito armado; pelos direitos dos refugiados; além de serem tutelados pelo sistema propriamente chamado de direitos humanos, seja de cunho universal (Nações Unidas) ou regional (continentes americano, europeu e africano). ${ }^{1}$

1 HANASHIRO, Olaya Sílvia Machado Portella. O sistema interamericano de proteção dos direitos humanos. São Paulo: Editora da Universidade de São Paulo: Fapesp, 2001. p. 19. 
Assim, o direito internacional humanitário apresenta-se como uma fonte de proteção, com precedentes no surgimento do Direito humanitário da Liga das Nações e da Organização Internacional do Trabalho (OIT), constituindo um dos marcos inicial do processo de internacionalização dos direitos humanos. Nestes termos, Mazzuoli (2002) explica que o Direito humanitário foi criado no século XIX, para ser aplicável em caso de conflitos armados (guerra), com o propósito de estabelecer limites mínimos éticos à atuação do Estado, a fim de garantir a eficácia dos direitos fundamentais à dignidade humana. ${ }^{2}$

Os tratados de direitos humanos incorporam obrigações relativas aos direitos dos seres humanos e não dos Estados, tendo por fundamento um interesse público geral superior, o que dá aos tratados uma especificidade. Por outro lado, ao buscar a proteção do ser humano, a nível mais elevado possível, os tratados criam obrigações erga omnes para os Estados.

A efetivação dos direitos humanos supracitados apresenta grande potencial para promoção da proteção do meio ambiente, tanto em nível doméstico quanto internacional, entretanto, existe a desconfiança de que apenas isso não seja suficiente para se alcançar uma proteção ambiental efetiva. Primeiramente, porque os direitos humanos não alcançaram níveis de efetividade minimamente razoáveis para a grande maioria da população mundial, e, em segundo lugar, porque os direitos humanos estabelecidos tratam das questões ambientais reflexamente, faltandolhes precisão e força para enfrentar os graves e urgentes problemas ambientais (Barros, 2008; Alves, 2003).

A expressão direitos fundamentais apareceu na França, por volta de 1770. Atualmente, não existe um consenso firmado

2 MAZZUOLI, Valério de Oliveira. Direitos humanos e cidadania: à luz no novo direito internacional. Campinas: Minelli, 2002. p. 35. acerca da terminologia e do conceito de tais direitos. Mesmo na Constituição Federal Brasileira de 1988 (CF/88) existem divergências semânticas como, por exemplo, na expressão direitos humanos, estabelecida no artigo $4^{\circ}$, inciso III; direitos e garantias fundamentais, estabelecida no Título II, artigo $5^{\circ}, \S 1^{\circ}$; $d i$ reitos e garantias individuais, prevista no art. $60, \S 4^{\circ}$, inciso IV etc. ${ }^{3}$

Normalmente, se utiliza a expressão direitos fundamentais para designar os direitos elevados à categoria de fundamentais positivados em nível interno. A identificação daqueles direitos nos ordenamentos jurídicos dos variados países do globo segue critérios próprios. Já a expressão direitos humanos é usualmente utilizada para designar os direitos naturais (fundamentais) humanos, estabelecidos em nível externo, ou seja, nas declarações internacionais de direitos, tratados e convenções.

Segundo Comparato (2001), define os direitos humanos como direitos fundamentais da pessoa humana - considerada tanto no seu aspecto individual como comunitários - que correspondem a esta em razão de sua própria natureza (de essência ao mesmo tempo corpórea, espiritual e social) e que devem ser reconhecidos e respeitados por todo poder e autoridade, inclusive as normas jurídicas positivas, cedendo, não obstante, em seu exercício, ante as exigências do bem comum.

Já na concepção de Robles, os direitos humanos são uma forma de referência a critérios morais; já os direitos fundamentais são autênticos direitos subjetivos privilegiados, dotados de um tratamento normativo e processual especial no ordenamento jurídico, se comparados aos demais direitos ordinários. ${ }^{4}$

\footnotetext{
3 KRETZ, Andrietta. Autonomia da vontade e eficácia horizontal dos direitos fundamentais. Florianópolis: Momento Atual, 2005. p. 49 e 51.

4 ROBLES, Gregório. Os direitos fundamentais e a ética na sociedade atual. Tradução de Roberto Barbosa Alves. Barueri, SP: Manole, 2005. p. 8-9.
} 
Foi a partir do século XV que se destacou o pensamento humanista, e, sobretudo, as idéias de Hobbes, e de Locke, que desenvolveram teorias políticas que contribuíram para a autodeterminação do indivíduo, além da sua liberdade, a fim de se impor um limite jurídico à arbitrariedade dos homens. Para isso, concebeu-se o Estado de Direito, contrapondo-se ao Estado Absolutista da época. No entanto, cabe destacar que muitas das promessas da modernidade - veiculados por meio do antropocentrismo e a razão individualista - não foram cumpridas, e seus benefícios foram distribuídos de forma desigual, resultando numa pós-modernidade maculada pela desigualdade, pobreza, riscos ambientais, entre outros graves problemas (Bobbio, 1992).

A internacionalização dos direitos humanos deu-se, com maior propriedade, a partir do segundo pós-guerra, em 1945, onde ocorreu a proliferação daqueles direitos, e dentro deles os direitos relativos ao meio ambiente. Assim, a Segunda Guerra Mundial, época em que ocorreram inúmeras violações de direitos, teve como conseqüência posterior uma intensa criação de normas internacionais de proteção do ser humano, com o objetivo de resguardar e tutelar direitos até então inexistentes juridicamente (Trindade, 1991).

De acordo com a realização da conferência em São Francisco, em junho de 1945, foi firmada a Carta de fundação da Organização das Nações Unidas, ou seja, a Carta da ONU. O item 3. do artigo $1^{\circ}$, desta Carta estabelece o propósito de se "conseguir uma cooperação internacional para resolver os problemas internacionais de caráter econômico, social, cultural e humanitário, e para promover e estimular o respeito aos direitos humanos e as liberdades fundamentais para todos, sem distinção de raça, sexo, língua ou religião" (ONU, 2010).

Em dezembro de 1948, a Assembléia
Geral das Nações Unidas aprovou a Declaração Universal dos Direitos Humanos, estabelecendo como objetivo a ser perseguido por todos os povos e nações, o esforço, por meio da educação, para promover o direito aos direitos e liberdades; além de incentivar a adoção de medidas progressivas de caráter nacional e internacional, a fim de se garantir e reconhecer a observância universal e efetiva dos direitos ali estabelecidos. O documento em questão declara, em seu artigo $1^{\mathrm{o}}$, que "todos os homens nascem livres e iguais em dignidade e direitos. São dotados de razão e consciência e devem agir em relação uns aos outros com espírito de fraternidade." Destaque-se que, a partir daquele evento histórico, os direitos humanos foram sendo formulados teoricamente, e depois positivados na legislação interna de cada país, transformando-se em direitos fundamentais (ONU, 2010).

É importante destacar que com relação à evolução dos direitos fundamentais, Schäfer (2005), comenta que estes evoluíram juntamente com o Estado de Direito, já que, com o processo de criação deste modelo de Estado, houve a necessidade de instituição de um controle dos órgãos estatais, a fim de se garantir o limite de suas competências mediante a vinculação do Poder Executivo ao ordenamento jurídico.

No aspecto mais globalizado, a discussão acerca dos direitos humanos se aprofundou nos últimos anos, mas ainda se privilegia, na prática, a concretização ou realização, sobretudo, dos direitos civis e políticos, assim como a consecução dos direitos econômicos, sociais e culturais apenas para determinados países, geralmente desenvolvidos; e para determinados grupos no interior dos países em desenvolvimento, contrariando o que é proclamado na Declaração Universal, de que "todos os homens nascem livres e iguais em dignidade e direitos".

No Brasil, a universalidade dos direi- 
tos humanos consolida-se, com a consagração do princípio constitucional da dignidade da pessoa humana como núcleo informador da interpretação de todo o ordenamento jurídico, tendo em vista que a dignidade é inerente a toda e qualquer pessoa. Quanto à indivisibilidade daqueles direitos, a $\mathrm{CF} / 88$ integra no elenco dos direitos fundamentais os direitos sociais, que nas Constituições anteriores estavam inseridos no capítulo relativo à ordem econômica e social (Venosa, 2010; Diniz, 2009).

\section{A IMPORTÂNCIA DE "TER UM DIREITO"}

A necessidade de se falar sobre direitos, é importante que tenha uma noção um pouco mais precisa do que significa "ter um direito". Um direito, de forma muito geral, é a possibilidade de agir ou o poder de exigir uma conduta dos outros, tanto uma ação quanto uma omissão. Por exemplo, a Constituição Federal, em seu artigo $5^{\circ}$, diz que todo brasileiro tem direito à liberdade de expressão. Isso significa que temos a possibilidade de expressar livremente nossas convicções religiosas, mas também que podemos exigir que os outros principalmente o Estado ou os membros de outras religiões, não criem obstáculos à nossa liberdade de culto (Venosa, 2010; Diniz, 2009; Dallari, 2005).

Não obstante, pode-se observar que a cada direito corresponde um dever. $\mathrm{Na}$ realidade, quando ocorre a expressão, por exemplo, que "a pessoa humana tem o direito à vida", está-se exigindo o direito de não morrer injustamente, o que significa que os outros têm o dever de respeitar a vida de outrem. Ter um direito, por conseguinte, é ser beneficiário de um dever correlativo por parte de outras pessoas ou do próprio Estado. Para cada classe de direitos existentes, há pessoas ou instituições com deveres correlatos. Se, como $\operatorname{diz}$ a $\mathrm{CF} / 88$, temos direito à educação, isso significa que o Poder Público (governos e prefeituras) tem a obrigação de construir escolas e assegurar que o ensino público e gratuito seja oferecido a todas as pessoas. Dizer que existe um dever correspondente a um direito não significa que os direitos possuam necessariamente eficácia, isto é, que eles sempre consigam produzir efeitos concretos na realidade. É possível que a pessoa humana tenha um direito com um dever correspondente, mas que, por alguma razão, não seja observado. Se uma pessoa procurar por um hospital público e não conseguir ser atendida, por exemplo, o Estado estará deixando de cumprir seu dever. Por conseguinte, o direito à saúde não está tendo a devida eficácia. De qualquer forma, os direitos dependem da existência de leis, juízes, advogados etc. Porém, muito dificilmente eles serão observados se a pessoa humana não tiver consciência e capacidade de organização para lutar por eles para atender suas necessidades (Bertoldi, 2010).

Neste diapasão, direitos são uma razão para agir ou o poder de exigir dos outros um determinado comportamento. À primeira vista, tal possibilidade decorre das normas jurídicas existentes na sociedade ou dos acordos que firmamos com os outros. Por exemplo, temos o direito à liberdade religiosa porque a Constituição Federal assim estabeleceu em seu artigo $5^{\circ}$. Por outro lado, temos o direito de cobrar o cumprimento de uma promessa feita, simplesmente porque alguém aceitou voluntariamente tal compromisso. Contudo, muitos filósofos acreditam que os direitos guardam relação com a forma como pensamos o que é o ser humano e como deve ser sua relação com os outros seres humanos. Não há uma única maneira de se pensar tais assuntos, mas ao menos, no caso da cultura ocidental, predomina a idéia de que os seres humanos são detentores de determinados direitos em razão de sua dignidade, 
isto é, do valor absoluto que eles possuem (Dallari, 2005; Comparato, 2001).

Segundo o filósofo alemão Immanuel Kant citado por Alexy (1997), pode-se avaliar as coisas pelo preço ou pela dignidade. Tudo aquilo que pode ser substituído por algo equivalente, tem um preço. Um objeto, um produto, um serviço, tudo isso pode receber um preço econômico ou um valor afetivo. Contudo, existe algo que não pode ser substituído por nada de equivalente e que é a própria vida humana. Cada ser humano é único e irrepetível. Por isso mesmo, ao contrário das coisas, os seres humanos não têm preço ou valor, mas possuem dignidade, isto é, um valor incondicionado e absoluto que ultrapassa todos os valores. Diferentemente das coisas, os seres humanos são pessoas, termo jurídico que designa exatamente o detentor de direitos. Por isso mesmo, os seres humanos devem ser sempre tratados com respeito, isto é, como um fim em si mesmo. Cada vez que usamos alguém como coisa, isto é, como instrumento para a obtenção de algo, estamos a violar a sua dignidade e, conseqüentemente, a desrespeitar seus direitos fundamentais.

\section{OS DIREITOS HUMANOS}

O conceito de pessoa para os fins jurídicos tem gerado divergência na doutrina. A pessoa é sujeito de direitos e obrigações, segundo o Código Civil, que no artigo $1^{\circ}$ diz que toda pessoa é capaz de direitos e deveres na ordem civil.

nior ${ }^{5}$ :

Ensina Tércio Sampaio Ferraz Jú-

"Em que pese às dificuldades de fundamentação, as noções de sujeito jurídico, pessoa física e pessoa jurídica são correntes na dogmática. Talvez uma explicação razoável des-

5 Ferraz Júnior. Tércio Sampaio. Introdução ao Estudo do Direito, 4a Edição, São Paulo, Atlas, 2003, pág. 156. ses conceitos possa ser encontrada na noção referida e papel social. A idéia reporta-se à origem da palavra pessoa - persona - que era máscara do ato no teatro. $\mathrm{O}$ mesmo indivíduo representa vários papéis (no teatro antigo, pondo a máscara). A própria sociedade institucionalizada os papéis como condição de interação. Conhemo-nos e interagimos, porque conhecemos os papéis assumíveis: o pai, o filho, o pagador de impostos, o motorista, o vendedor, o comerciante. Os papéis institucionalizados normativamente, no direito, ganham contornos certos e seguros. O papel de juiz não é apenas aquele que julga pendências, mas depende de um estatuto próprio, o estatuto da magistratura. $\mathrm{O}$ estado confere papel as qualidades que o tornam consistente para o intercâmbio jurídico. Nesses termos, o que chamamos de pessoa nada mais é do que feixe de papéis institucionalizados".

Para fins civis, ensina Maria Helena Diniz ${ }^{6}$ :

"Liga-se à pessoa a idéia de personalidade, que exprime a aptidão genérica para adquirir direitos e contrair deveres. O novel Código Civil preferiu empregar o termo deveres, alerta Fiúza, no relatório geral, por existirem deveres jurídicos diferentes da obrigação, como a sujeição nos direitos de vizinhança, o dever genérico de abstenção, os poderesdeveres e os deveres dos direitos de família".

Para Nélson Nery Júnior e Rosa Maria de Andrade $\mathrm{Nery}^{7}$ :

6 Diniz, Maria Helena, Código Civil Anotado, $11^{a}$ Edição, São Paulo, Saraiva, 2005, pág. 04.

7 Nery Nélson; Andrade Nery Rosa Maria. Código Civil Comentado e legislação Extravagante, $3^{\mathrm{a}}$ Edição, São Paulo, RT, 2005, pág. 161 . 
"Pessoa natural é sinônimo de pessoa física, ser humano. É termo utilizado para distinguir o homem de outros titulares de direito que o são por processo artificial de ficção jurídica. O termo pessoa identifica, dentro de um mesmo livro, as duas espécies de pessoas (sujeito de direito): pessoa natural (Título I) e pessoa jurídica (Título II)".

Sobre o princípio da dignidade da pessoa humana, ensina Ingo Wolfgong Sarlet ${ }^{8}$ :

"O problema do significado que se pode hoje atribuir à dignidade da pessoa humana, cumpre ressaltar de início, que a idéia do valor intrínseco da pessoa humana deita raízes já no pensamento clássico e no ideário cristão. Muito embora não nos pareça correto, inclusive por faltar dados seguros quanto a este aspecto, reivindicar - no contexto das diversas religiões professadas pelo ser humano ao longo dos tempos - para a religião cristã a exclusividade e originalidade quanto à elaboração de uma concepção de dignidade da pessoa, o fato é que tanto no Antigo quando no Novo Testamento podemos encontrar referências no sentido de que o ser humano foi criado à imagem e semelhança de Deus, premissa da qual o cristianismo extraiu a conseqüência - lamentavelmente renegada por muito tempo por parte das instituições cristãs e seus integrantes (basta lembrar as crueldades praticadas pela 'Santa Inquisição') - de que o ser humano - e não apenas o cristãos - é dotado de um valor próprio e que lhe é intrínseco, não podendo ser transformado em

8 Sarlet, Ingo Wolfgang. Dignidade da Pessoa Humana e Direitos Fundamentais, $4^{\mathrm{a}}$ Edição, Porto Alegre, Livraria do Advogado Editora, 2006, págs. 29/30. mero objeto ou instrumento" .

Nesse diapasão, oportunas as palavras de Flávia Piovesan ${ }^{10}$ :

"O valor da dignidade humana impõe-se como núcleo básico e informador do ordenamento jurídico brasileiro, como critério e parâmetro de valoração a orientar a interpretação e compreensão do sistema constitucional instaurado em 1988. A dignidade humana e os direitos fundamentais vêm constituir os princípios constitucionais que incorporam as exigências de justiça e dos valores éticos, conferindo suporte axiológico a todo o sistema jurídico brasileiro. $\mathrm{Na}$ ordem de 1988 esses valores a ser dotados de uma especial força expansiva,

9 Conforme Carlos Augusto Ayres de Freitas Brito: "Péricles, um pensador e um administrador grego de nomeada, chegou a dizer, a propósito desse experimento grego de cidadania em tempo integral, que aquele que não se interessa pelos assuntos da polis não é apenas uma pessoa que não se interessa pelos assuntos da polis, é um inútil. De maneira que as mulheres, o adolescentes, as criança, os escravos, os estrangeiros, os povos conquistados não tinham maior dignidade jurídica. Os gregos não diziam, como dizemos hoje: Participo porque sou livre. Os gregos diziam: 'Sou livre porque participo'. Então, não havia essa distinção, essa dignidade do trabalhador, do inativo, do religiosos, se não estivesse tudo acoplado à dimensão cidadã. $\mathrm{O}$ que interessava era o cidadão. Uma espécie de totalitarismo que a Rússia tentou revitalizar ou ressuscitar, atualizadamente, com a sua Revolução de 1918. Mas esse conceito acanhado de dignidade da pessoa humana, já na própria Grécia, encontrava algumas reações episódicas, porém sem sucesso. Por exemplo: Protágoras dizia numa frase definitiva e, portanto, de marcante atualidade, que o homem era a medida de todas as coisas; Buda, fora da Grécia - Buda antecipou Cristo 500 anos -, também enxergava no homem um ser potencialmente iluminado, de sorte a pressentir na ontologia humana a própria chamada da divindade. Buda também cunhou uma frase, que está nos albores da dignidade da pessoa humana no plano teórico: 'Não acredite em certa coisas só porque as sagradas escrituras dizem que é assim, não acredite em certas coisas só porque o povo todo diz que é assim; não acredite em certas coisas só porque eu estou dizendo que é assim; a mesmos que você experimente, siga duvidando até o fim'. Então, Buda prestigiava a experiência humana, valorizada a individualidade; cada ser humano que tratasse do seu próprio caminho e encontrasse sua própria verdade. Buda antecipou São Tomé, que só acreditava no que via. E, de certa forma, antecipou Niestzche, que também proferiu este pensamento fecundo: 'Quem quiser me seguir, não me siga; ou seja siga você mesmo'. Alias, Gilberto Gil, 'niestzchianamente', numa música antiga chamada 'Aquele Abraço', dizia: 'Meu caminho pelo mundo eu mesmo traço, a Bahia já me deu régua e compasso'. Isso é o reconhecimento dessa dignidade inerente a todo ser humano"(Constitucionalismo Fraterno e o Direito do Trabalho, in Fórum Internacional sobre Direitos Humanos e Direitos Sociais, São Paulo, LTR, 2004, pág. 46), Sarlet (2002).

10 Piovesan, Flávia. Direitos Humanos e o Trabalho, Revista da amaratra II, São Paulo, 2003, pág. 13. 
projetando-se por todo o universo constitucional e servindo como critério interpretativo de todas as normas do ordenamento jurídico nacional. A Constituição de 1988 acolhe a idéia da universalidade dos direitos humanos, na medida em que consagra o valor da dignidade humana como princípio fundamental do constitucionalismo inaugurado em 1988. O texto constitucional ainda realça que os direitos humanos são temas de legítimo interesse da comunidade internacional, ao ineditamente prever, dentre os princípios a reger o Brasil nas relações internacionais, o princípio da prevalência dos direitos humanos. Trata-se, ademais, da primeira Constituição Brasileira a incluir os direitos internacionais no elenco dos direitos constitucionalmente garantidos. Ao fim da extensa Declaração de Direitos enunciada pelo art. $5^{\circ}$, a Carta de 1988 estabelece que os direitos e garantias expressos na Constituição 'não excluem outros decorrentes do regime e dos princípios por ela adotados ou dos tratados internacionais em que a República Federativa do Brasil seja parte'. A Constituição de 1988 inova, assim, ao incluir, dentre os direitos constitucionalmente protegidos, os direitos enunciados nos tratados internacionais de que o Brasil seja signatário. Ao efetuar tal incorporação, a Carta está a atribuir aos direitos internacionais uma hierarquia especial e diferenciada: a hierarquia constitucional."

Os direitos humanos são todos aqueles direitos inerentes às pessoas humanas, visando à proteção das mesmas, que podem ser aceitos por todas as culturas, ou seja, por todos os povos da terra em todos os Estados Soberanos (Dallari, 2005).
$\mathrm{Na}$ doutrina mundial, existe uma classificação histórica dos direitos humanos, que os distingue em Direitos Humanos de Primeira, Segunda e Terceira Geração. ${ }^{11}$

Os Direitos Humanos de Primeira Geração surgiram no cenário mundial na Revolução Francesa, em 1789, e foram preservadas as garantias individuais do ser humano, os direitos civis e políticos.

A Segunda Geração dos Direitos Humanos em espécie, surgiu em meados do séc. XIX, com a Revolução Industrial, e tem como principal marca, o papel do Estado, que passou a ser o mediador de conflitos coletivos, tendo sua atuação na economia, na proteção dos trabalhadores e na implementação de políticas visando o desenvolvimento social (Dallari, 2005).

Já os Direitos Humanos de Terceira Geração, são mais recentes, e tratam especificamente dos direitos difusos. Sua primeira manifestação ocorreu durante e após a Segunda Guerra Mundial e estão consubstanciados na Carta das Nações Unidas e outras tantas convenções internacionais. A doutrina entende como direitos humanos de Terceira Geração, os direitos de solidariedade, a proteção do patrimônio histórico, cultural e ambiental, com a intenção de repreender os danos ambientais, e assegurar uma vida digna, para as gerações presentes e futuras.

De acordo com Comparato (2001), terceira geração de direitos humanos qual seja, a fraternidade, está ligada especialmente à qualidade de vida e à solidariedade entre os seres humanos. Dessa forma, ele afirma que os principais direitos de solidariedade são: o direito à paz, o direito ao desenvolvimento, o direito ao meio ambiente e o direito ao patrimônio comum da humanidade.

Neste diapasão, a doutrina passou a considerar como Direito Humano de Tercei-

11 FACIN, Andréia Minussi. Meio ambiente e direitos humanos Jus Navigandi, Teresina, ano 7, n. 60, nov. 2002. Disponível em: $<$ http://jus2.uol.com.br/doutrina/texto.asp?id=3463>. Acesso em: 03 jul. 2010. 
ra Geração o direito a um ambiente digno e sadio, quando se viola o direito ao meio ambiente, também se viola os direitos e a dignidade da pessoa humana.

A validação de direitos humanos comungada com o direito a um ambiente sadio está consignada na terceira geração de direitos humanos na qual incentiva o fortalecimento das prerrogativas e do poder de polícia administrativa das instituições encarregadas de promover a proteção do patrimônio histórico, cultural e ambiental, legitimada a repreender os danos ambientais por meio do discurso da “preservação ambiental". A cada geração dos direitos humanos, um dos poderes do Estado é destacado. Enquanto os direitos humanos de primeira geração dependem do Legislativo e do Judiciário, por terem sido forjados como forma de proteção contra o poder do Estado, os direitos humanos de segunda e terceira geração exigem, para sua concretização, uma atuação positiva do Executivo. Mas estas gerações enfrentam problemas quanto à sua efetivação. ${ }^{12}$

$\mathrm{Na}$ medida em que o capitalismo se desenvolve, a violação aos direitos humanos se acentua, tendo em vista as dificuldades do atual regime democrático brasileiro, composto por uma heterogeneidade de classes econômicas e interesses políticos. Este quadro direcionou os discursos de preservação ambiental em torno das razões produtiva e econômica, ao invés de destiná-los a uma política de manejo dos recursos naturais que possibilitasse reintegrar o homem ao ambiente, de modo a conseguir a mais alta qualidade de vida humana sustentada (Barros, 2008; Campilongo, 2002).

Neste contexto, pode-se constatar que os habitantes das populações tradicionais, excluídos do mercado de trabalho, ao buscar sua sobrevivência por meio de recursos ex-

12 Renata Maciel Cuiabano. A Questão Ambiental Frente Aos Direitos Humanos. Portal Boletim Jurídico. Ano VIII Número 650 . traídos do meio ambiente, acabaram perdendo condições materiais para exercer em toda sua plenitude seus direitos. "A civilidade para o pobre", considerado pelo pensamento culto, um ser semi racional, implicou a noção de disciplina, algo que do exterior constrange as pessoas a um comportamento previsível e formador de uma segunda natureza do homem sem o recurso à inteligibilidade dos pressupostos ou à consciência de sua importância.

$\mathrm{O}$ que se convencionou chamar "direitos humanos" são exatamente os direitos correspondentes à dignidade dos seres humanos. São direitos que possuímos não porque o Estado assim decidiu, através de suas leis, ou porque nós mesmos assim o fizemos, por intermédio dos nossos acordos. Direitos humanos, por mais pleonástico que isso possa parecer, são direitos que possuímos pelo simples fato de que somos humanos. Essa é uma idéia profundamente revolucionária, e muitos sacrifícios foram necessários para que chegássemos até ela. A história da maldade humana é longa e assustadora, e a lista dos mortos sempre ultrapassou a casa dos milhões. Milhões de negros africanos capturados, traficados e transformados em escravos por toda a América. Milhões de índios dizimados por guerras e doenças trazidas pelos colonizadores. Milhões de judeus mortos pelos nazistas em campos de concentração (Shäfer, 2005; Alves, 2003).

Neste contexto, foi contra essas deploráveis barbáries que construímos o consenso de que os seres humanos devem ser reconhecidos como detentores de direitos inatos, ainda que filosoficamente tal idéia venha a ensejar grandes controvérsias. Por exemplo, o Estado poderia desejar matar todos os suspeitos de cometerem delitos em nome da redução da criminalidade. Contudo, caso isso viesse a acontecer, poderíamos evocar em nossa defesa a existência de valores mais importantes, tais como a vida e a inte- 
gridade física dos seres humanos. Na metáfora de um jogo que estaríamos a jogar contra o Estado, tais valores funcionariam como trunfos ou coringas.

Por outro lado, isso não significa que todos os direitos sejam absolutos, no sentido de que devam ser observados de forma incondicional. Afinal, o direito que tenho à liberdade de expressão não me autoriza a sair por aí ofendendo as outras pessoas, pois estas também têm direito à honra e à vida privada. $\mathrm{Na}$ verdade, todo direito precisa ser ponderado, de modo que possamos avaliar seu peso ou importância, bem como sua compatibilidade com o interesse coletivo.

\section{SUJEITOS E OBJETOS DOS DIREITOS HUMANOS}

É bem verdade de que a pessoa humana quando dispõe de um direito, é chamada de sujeito de direito. Por outra parte, matéria ou assunto do qual o direito trata, recebe o nome de objeto de direito. $\mathrm{O}$ direito à liberdade religiosa, por exemplo, tem como sujeito os indivíduos ou grupos que desejam expressar uma convicção religiosa. O objeto deste direito, por sua vez, também chamado de "bem jurídico protegido", é a própria liberdade em questão. Os sujeitos de direitos podem ser individuais ou coletivos. $\mathrm{O}$ direito de votar e ser votado, por exemplo, é um direito individual. $\mathrm{O}$ direito de greve, em contrapartida, é um direito coletivo (Diniz, 2009).

Com efeito, a história dos direitos humanos pode ser vista como um processo de expansão dos sujeitos de direitos e dos objetos correspondentes. Os primeiros direitos humanos, que surgiram no século XVIII, são os chamados direitos civis e políticos. Os sujeitos destes direitos são os indivíduos; os objetos sobre os quais eles versam, por sua vez, são as liberdades individuais (liberdade de ir e vir, liberdade de expressão, liberdade de crença etc.). Por isso mesmo, os direitos ci- vis e políticos são também conhecidos como “direitos-liberdade". No século XIX, por sua vez, apareceram os direitos sociais, econômicos e culturais, cujos sujeitos são também os indivíduos, só que agora considerados do ponto de vista coletivo e no plano da distribuição dos recursos sociais. São os chamados "direitos-prestação", posto que exigem uma intervenção por parte do Estado de maneira a suprir as necessidades mais básicas dos indivíduos e a propiciar o próprio exercício das liberdades individuais. A diferença entre um direito-liberdade e um direito-prestação pode ser compreendida a partir do seguinte exemplo: de acordo com a Constituição Federal brasileira, temos o direito de ir e vir livremente, porém tal direito nunca poderá ser plenamente exercido se não dispomos de transporte público, não temos dinheiro para comprar a passagem, ou caso sejamos portadores de uma necessidade especial, se não existem rampas para a cadeira de rodas que utilizamos (Comparato, 2001; Alexy, 1997).

$\mathrm{O}$ século $\mathrm{XX}$ foi o mais rico do ponto de vista da expansão dos direitos humanos. Nele surgiram os "direitos difusos", assim denominados porque não têm um sujeito específico, mas interessam à humanidade como um todo (direito ao desenvolvimento, direito à paz, direito ao meio ambiente protegido etc.). Posteriormente, o mesmo século deu lugar a direitos mais "exóticos" que tratam dos animais, da natureza e dos embriões, por exemplo. Pode-se dizer que os sujeitos dos direitos humanos conheceram, ao longo da história, não apenas uma expansão, mas também um interessante processo de especificação. Os direitos humanos clássicos não valorizavam os elementos de diferenciação de um indivíduo com relação ao outro (gênero, etnia, idade, opção sexual etc.), mas concebiam seus titulares de forma genérica e abstrata (o homem, o cidadão etc.). $\mathrm{Na}$ contemporaneidade, ao contrário, os direitos humanos tendem a vislumbrar os sujeitos de 
forma concreta e particular, isto é, como indivíduos historicamente situados, inseridos numa estrutura social, e portadores de necessidades específicas. Daí falarmos de "direitos das mulheres", "direitos das crianças", "direitos dos portadores de deficiência" e "direitos dos homossexuais", dentre outros direitos da pessoa humana (Campilongo, 2002; Bobbio, 1992).

Outros acusam os direitos humanos de serem uma criação arbitrária da cultura ocidental, uma cultura profundamente individualista e egoísta, na qual os indivíduos se vêem como células circundadas por direitos, e não como membros que fazem parte de um todo e que têm deveres com relação ao mesmo. Por fim, alguns estimam que a idéia de direitos humanos exerça o papel ideológico de manutenção da ordem dominante, impedindo reformas políticas e sociais. Afinal, do que adianta dizer que brancos e negros, homens e mulheres, e assim por diante, têm o mesmo direito, se as desigualdades sociais e econômicas, que dividem a sociedade, teimam em persistir? Tais críticas são instigantes, mas elas suscitam respostas razoáveis por parte dos defensores dos direitos humanos. É certo que a idéia de dignidade humana como fundamento dos direitos humanos é filosoficamente questionável. De fato, o que poderia justificar, fora de uma perspectiva religiosa ou dogmática, a indistinta atribuição aos seres humanos de um mesmo valor? No entanto, podemos argumentar contra esta crítica dizendo que a dignidade é o valor que atribuímos aos seres humanos em função das nossas crenças sobre o modo como os mesmos devem ser tratados. Vimos tantas injustiças e tantos atos bárbaros serem cometidos contra a humanidade, que fomos levados a formar a convicção de que os homens precisam ser reconhecidos como titulares de direitos básicos (Dallari, 2005; Comparato, 2001).

A crítica de que os direitos humanos representam um ponto de vista de uma cultu- ra ocidental de traço profundamente egoísta pode ser rebatida a partir de vários argumentos. Em primeiro lugar, não está provado que os direitos humanos sejam produto genuíno da cultura ocidental ou algo incompatível com determinadas culturas. Por outro lado, mesmo que esta crítica esteja fundada, isso significa apenas que os direitos humanos não são universais, e não que eles não poderiam ser universalizados de forma democrática e respeitadora da diversidade cultural. Por fim, é bem verdade que uma boa parcela dos direitos humanos guarda relação com liberdades individuais, o que parece ser típico de uma sociedade individualista, mas não podemos esquecer os vários direitos que acentuam uma vida solidária, tais como os direitos sociais, por exemplo (Campilongo, 2002; Trindidade, 1991).

E por fim, a última crítica, por sua vez, pode ser respondida a partir da idéia de que os direitos humanos, mesmo não questionando as bases de uma sociedade capitalista, podem servir como um instrumento à construção de uma sociedade justa e solidária. Em outras palavras, os direitos à dignidade humana não são uma panacéia contra todos os males sociais e econômicos, mas sem eles, dificilmente, poderemos aspirar por um mundo decente e eqüitativo.

A história dos direitos humanos no Brasil pode ser vista como obra de todos aqueles que, através de insurreições, rebeliões e revoltas, lutaram contra uma estrutura de dominação que vigorou em nosso país durante séculos e que ainda persiste em muitos aspectos, principalmente no que concerne às desigualdades sociais (Bobbio, 2002; Chagas, 1998).

Por isso mesmo, a idéia de direitos humanos em nosso país permanece sendo vista como algo subversivo e transgressor. Nas últimas décadas, as classes populares e os movimentos sociais têm feito um uso intenso dos direitos humanos como instrumen- 
to de transformação da ordem dominante, o que explica a ação enérgica de determinados grupos conservadores, no sentido de tentar associar a causa dos direitos humanos à mera defesa das pessoas que cometeram um delito. Daí acusações falsas do tipo: "direitos humanos é coisa de bandido" ou "onde estão os direitos das vítimas?".

Estas acusações não procedem. Afinal, os direitos á dignidade humana, ultrapassam largamente a esfera penal. Certo, muitas organizações, como a Anistia Internacional, lutam pelos direitos das pessoas encarceradas. Mas outras entidades, como o Greenpeace, por exemplo, existem para a defesa do meio ambiente. $\mathrm{Na}$ verdade, para cada direito humano reconhecido no processo de expansão, existem dezenas ou centenas de organizações militantes. O mesmo ocorre com relação às vítimas de delitos. O GAJOPE (Grupo de Apoio Jurídico às Organizações Populares), por exemplo, é uma entidade brasileira que presta assistência deste tipo. Contudo, sempre é bom lembrar que, mesmo as pessoas que cometeram delitos graves, têm direitos básicos que devem ser respeitados. Quem comete um delito, pode perder sua liberdade (em alguns países até a vida), mas nunca sua dignidade (Bobbio, 1992; Trindade, 1991).

Assim como a amizade e o amor, os direitos precisam ser cultivados, pois não existe qualquer garantia de que este importante patrimônio moral da humanidade permaneça intocado. Recebemos todos os dias, de diversas partes do mundo, notícias sobre graves violações e ameaças aos direitos humanos. De onde a importância da educação em direitos humanos, concebida não como a simples introdução de um conteúdo temático sobre tais direitos nos programas escolares ou universitários, mas essencialmente como um meio capaz de proporcionar a construção de uma cidadania ativa em nosso país. Este é o desafio que se impõe ao conjunto da sociedade brasileira, principalmente aos mais jovens.

\section{DIREITOS HUMANOS AMBIENTAL}

A busca pela efetivação do direito a um ambiente sadio e do direito ao desenvolvimento como direito à dignidade humana passa por soluções da melhoria das condições de vida de quase dois terços da população mundial, como a erradicação da pobreza, a promoção da saúde, da educação e da nutrição, a redução do déficit de moradias ou o acesso a elas, a planificação da urbanização e do crescimento demográfico, a eliminação dos impactos e danos ambientais, o desarmamento, entre outros fatores, já reconhecidos em relatórios internacionais (Barros, 2008; Facin, 2002).

O marco inicial do direito ao meio ambiente no Brasil é a edição da Lei da Política Nacional do Meio Ambiente de 1981, ainda vigente, substituindo a antiga legislação antes setorizada. Esta lei instituiu o Sistema Nacional de Meio Ambiente (SISNAMA), visando harmonizar o desenvolvimento socioeconômico e o meio ambiente, mediante a adoção de condições para o desenvolvimento sustentável, ou seja, explorando os recursos naturais conscientemente, de acordo com os interesses da segurança nacional, garantindo principalmente a proteção da dignidade da vida humana (Barros, 2008; Marum, 2002).

Por outro lado, é evidente que o Programa das Nações Unidas para o Desenvolvimento (PNUD) defende que o conceito de desenvolvimento humano há de ser relacionado ao direito ao desenvolvimento como um direito humano e defende que especial atenção deve ser dada à consciência e educação ambientais, vez que o direito a um ambiente sadio é ao mesmo tempo, um direito individual e coletivo (difuso).

É importante observar que o art. III da Declaração Universal dos Direitos Humanos (1948) diz que toda pessoa tem direito à vida, à liberdade e à segurança pessoal. Ora, quando diz “à vida” incluído está o meio ambiente 
equilibrado, pois este é uma das condições essenciais à existência da vida em toda a sua plenitude e formas.

Neste diapasão, a Constituição brasileira reconhece a interligação e interdependência entre as questões ambientais, econômicas e de promoção do ser humano, ao inserir os princípios da dignidade da pessoa humana e da defesa do meio ambiente no seu artigo 170, inciso VI, como princípios gerais da atividade econômica, o que representa um avanço normativo na construção de uma sociedade democrática sustentável (Barros, 2008).

Neste contexto, pode-se inferir de tal sorte que o meio ambiente é onde se expande à vida humana e o mínimo que o ser humano pode fazer, é preservá-lo. Por isto, todo o desenvolvimento econômico-social deve ser compatibilizado com a presunção da qualidade do meio ambiente e do equilíbrio ecológico. Nesse sentido, os direitos humanos estão cada vez mais se ampliando, e dentre os mesmos, pode-se atualmente vislumbrar, o direito a um meio ambiente sano, o que demonstra o anseio da sociedade por uma vida com qualidade.

No que diz respeito à nossa legislação podemos destacar a própria Constituição Federal Brasileira de $1988^{13}$, onde existem importantes artigos referentes aos direitos humanos como o art. $1^{\circ}$, inciso III que protege a dignidade humana e a coloca como fundamento da República; art. $3^{\circ}$, inciso III que põe como objetivos fundamentais, entre outros, a erradicação da pobreza e da marginalização a fim de reduzir a desigualdade social e regional; art. $5^{\circ}$, caput, que coloca todos iguais perante a lei, e seu inciso III, que proíbe a tortura, o tratamento desumano ou degradante; $\operatorname{art.} 6^{\circ}$ que determinada a assistência aos

13 Constituição da República Federativa do Brasil de 1988. Disponível em:

$<$ http://www.planalto.gov.br/ccivil_03/Constituicao/ Constitui\%C3\%A7ao.htm>. Acesso em:

02 julho 2010. desamparados; art.193 que dá como base da ordem social o bem estar e a justiça social; art.231 que reconhece aos índios sua organização social como um todo e o art.225 que reconhece o direito de todos a ter um meio ambiente equilibrado e sadio.

A proteção ao meio ambiente pode ser considerada como um meio para se conseguir o cumprimento dos direitos humanos, pois na medida em que ocorre um dano ao ambiente, consequentemente, haverá infração a outros direitos fundamentais do homem, como a vida, a saúde, o bem estar; direitos estes, reconhecidos internacionalmente (Barros, 2008; Marum, 2002).

$\mathrm{O}$ direito à vida, visto como um direito universal do ser humano visa estabelecer segurança e igualdade a todos os povos. Isto significa dizer, que se todas as Nações preservarem e contribuírem para um ambiente sadio, todos os povos estarão protegidos, independente de se considerar a classe econômica existente nos mesmos (Facin, 2002).

De acordo com Facin (2002), o direito humano e o direito a um ambiente sadio estão interligados, pois ambos buscam preservar à vida, ou melhor, a qualidade de vida na Terra. São direitos que, onde houver a violação de um, haverá do outro, posto que, se violados, invadem um o campo do outro, constituindo um duplo desequilíbrio, tanto ambiental quanto humano. Dessa forma, pode-se presumir que sempre que houver uma violação ao meio ambiente, haverá uma violação aos direitos à dignidade humana.

A Constituição Federal de 1988 foi a primeira a tratar expressamente da questão ambiental, precisamente no art. 225 e em outras normas constitucionais, seja de forma explícita ou implícita, a saber:

“Art. 225. Todos têm direito ao meio ambiente ecologicamente equilibrado, bem de uso comum do povo e essencial à sadia qualidade de vida, impondo-se ao poder público e à 
coletividade o dever de defendê-lo e preservá-lo para as presentes e futuras gerações. $\S 1^{\circ}$. Para assegurar a efetividade desse direito, incumbe ao poder público: I - preservar e restaurar os processos ecológicos essenciais e prover o manejo ecológico das espécies e ecossistemas; II - preservar a diversidade e a integridade do patrimônio genético do País e fiscalizar as entidades dedicadas à pesquisa e manipulação de material genético; III - definir, em todas as unidades da Federação, espaços territoriais e seus componentes a serem especialmente protegidos, sendo a alteração e a supressão permitidas somente através de lei, vedada qualquer utilização que comprometa a integridade dos atributos que justificam sua proteção; IV - exigir, na forma da lei, para instalação de obra ou atividade potencialmente causadora de significativa degradação do meio ambiente, estudo prévio de impacto ambiental, a que se dará publicidade; V - controlar a produção, a comercialização e o emprego de técnicas, métodos e substâncias que comportem risco para a vida, a qualidade de vida e o meio ambiente; VI - promover a educação ambiental em todos os níveis de ensino e a conscientização pública para a preservação do meio ambiente; VII - proteger a fauna e a flora, vedadas, na forma da lei, as práticas que coloquem em risco sua função ecológica, provoquem a extinção de espécies ou submetam os animais a crueldade. (...)"

$\mathrm{O}$ núcleo normativo do direito ambiental contido no artigo 225 da Carta Magna está dentro do título constitucional denominado da "Ordem Social", o que faz concluir, que o meio ambiente é um direito social do homem. Por este motivo, infere-se que o conteúdo da norma matriz inserida no mencionado artigo, é no sentido de que todos têm direito a um meio ambiente ecologicamente equilibrado. Destarte, o meio ambiente, passou, portanto, a ser considerado essencial para que o ser humano possa gozar dos direitos humanos fundamentais, dentre eles, o próprio direito à vida (Comparato, 2001).

A interligação existente entre os direitos humanos, formando o que se pode chamar de direitos humanos ambientais, é evidente e já foi declarada em normas positivadas de muitos países, ratificando ser direito da pessoa humana e das coletividades o de viver em ambiente sadio e equilibrado. Por outro lado, o desenvolvimento sócio-econômico e cultural dos povos deve ocorrer tendo em vista o paradigma da utilização racional dos elementos naturais, sob pena de se estar privando as populações do direito humano a uma vida digna (Barros, 2008).

Torna-se oportuno destacar que muitos doutrinadores e estudiosos do direito descrevem que enquanto alguns países incorporaram o direito humano ao ambiente em suas constituições outros apenas incluíram normas ambientais na legislação nacional, após a Conferência do Rio em 1992. A partir de então, vários países incorporaram normas de proteção ambiental em suas constituições segundo PNUMA (1992), tais como: ${ }^{14}$

a) A Lei Geral do Meio Ambiente da Bolívia de 1992 estabelece, no art. 17, que é dever do Estado e da sociedade garantir o direito de toda pessoa e ser vivo a desfrutar de um ambiente sadio e agradável, no desenvolvimento e exercício de suas atividades.

b) A Constituição Peruana reformada em 1993, dispõe no art. $2^{\circ}$, que toda pessoa tem o direito à paz, à tranqüilida-

14 PNUMA. Legislación ambiental general en america latina y el caribe. Série de legislacion ambiental n. 1. Ciudad de México: Oficina Regional para América Latina y el Caribe del PNUMA, 1992, p. 357. 
de e ao desfrute de tempo livre e ao descanso, assim como a gozar de um ambiente equilibrado e adequado.

c) A Lei de Bases Gerais do Meio Ambiente do Chile, de 1994, estabelece no art. $1^{\circ}$, que $o$ direito a viver em um meio ambiente livre de contaminação, à proteção do meio ambiente, à preservação da natureza e à conservação do patrimônio ambiental regular-se-á pelas disposições desta lei, sem prejuizo do que outras normas legais estabeleçam sobre a matéria.

d) A Constituição Argentina, reformada em 1994, estabelece no art. 41, que os cidadãos argentinos têm o direito a um meio ambiente sadio, equilibrado, apto para o desenvolvimento humano e para as atividades produtivas que satisfaçam as necessidades presentes sem comprometer as das gerações futuras, assim como o dever de conservá-lo. Incumbe-se às autoridades a efetivação deste direito, que deverão promover a utilização $\mathrm{O}$ direito fundamental à preservação do meio ambiente e o direito à vida, a nível mundial, foi reconhecido pela Declaração do Meio Ambiente, adotada na Conferência das Nações Unidas, em Estocolmo, em 1972.

e) A Constituição Política da República da Costa Rica, reformada em 1994, em seu art. 50, dispõe que o Estado procurará o maior bem-estar dos habitantes do país, organizando e estimulando a produção e a mais adequada distribuição de riqueza. Ao mesmo tempo, institui o direito de toda pessoa a um meio sadio e ecologicamente equilibrado, legitimando qualquer indivíduo a denunciar os atos que infrinjam esse direito e para reclamar a reparação do dano causado. Ao Estado cabe garantir a defesa e preservação desse direito, que determinará em lei, as responsabilidades e sanções cabíveis.

f) A Constituição Política da República da Nicarágua, reformada em 1995, dispõe no art. 60 que os nicaragüenses têm direito a habitar em um ambiente saudável, sendo obrigação do Estado à preservação, conservação e resgate do meio ambiente e dos recursos naturais.

g) A Lei Geral do Equilíbrio Ecológico e da Proteção Ambiental do México, reformada em 1996, dispõe no art. 15, XII, que toda pessoa tem direito a desfrutar de um ambiente adequado para seu desenvolvimento, saúde e bem-estar. As autoridades, em termos desta e outras leis, tomarão as medidas para garantir este direito. Em 1998, foi consagrado o direito ao meio ambiente, adicionando-se ao art. $4^{\circ}$ da Constituição Mexicana que toda pessoa tem direito a um meio ambiente adequado para seu desenvolvimento e bem-estar.

Neste diapasão, pela interpretação das normas independentemente de qualquer Estado soberano, conclui-se que o Direito Ambiental é um dos direitos fundamentais da pessoa humana, o que reforça a posição de que se trata de direitos humanos.

$\mathrm{O}$ direito ao ambiente como um dos direitos fundamentais da pessoa humana é um importante marco na construção de uma sociedade democrática, participativa e socialmente solidária. Por ora, a preocupação geral é de forma a resguardar o meio ambiente, visto que, a sua destruição afetará todos indistintamente, independentes de ter maiores ou menores condições financeiras. A proteção ao meio ambiente é relevante, na medida em que é importante preservar a natureza, como meio da própria subsistência e existência da vida humana (Facin, 2002). 
Para que os indivíduos e povos exerçam com plenitude o direito a uma vida digna, indispensável se faz à existência de um meio ambiente sadio, fonte de todos os recursos que garantirão a continuidade da vida no planeta. A exploração dos recursos naturais deve ser feita de forma economicamente planejada, tendo em vista a dimensão temporal da proteção ambiental, ou seja, o compromisso global entre todos os povos da humanidade (Trindade, 1993).

Portanto, o direito ao meio ambiente ecologicamente equilibrado é um direito fundamental, porque é uma prerrogativa individual prevista constitucionalmente, cuja realização envolve uma série de atividades públicas e privadas, produzindo não só a sua consolidação, como trazendo, em decorrência disto, uma melhora das condições de desenvolvimento das potencialidades individuais, bem como uma ordem social livre.

Existe um aspecto que é extremamente importante do qual se trata no inafastável ponto de ligação nos instrumentos de proteção dos direitos humanos e do meio ambiente: os instrumentos internacionais de direitos humanos sempre ressaltam a necessidade de se proteger o meio ambiente para se garantir a continuidade da vida no planeta. Da mesma forma, a proteção dos direitos humanos também é objeto do Direito Ambiental Internacional, pois, à medida que os instrumentos de direito ambiental têm por objetivo proteger o meio ambiente, estão, simultaneamente, protegendo os seres humanos e a humanidade. Estabelece-se, assim, um contínuo movimento: da proteção do meio ambiente resulta a proteção dos direitos humanos e vice-versa (Conceição, 2003; Marum, 2002).

Nesse contexto, a abordagem do direito a um meio ambiente sadio há de ser feita concomitantemente com o direito ao desenvolvimento, seja na dimensão individual ou coletiva, vez que ambos representam direitos humanos. As asserções dessa inter-relação têm ecoado em todas as partes, tendo a Assembléia Geral das Nações Unidas, ao convocar a Conferência das Nações Unidas sobre Meio Ambiente e Desenvolvimento, afirmado e insistido na promoção do desenvolvimento sustentável e ambientalmente sadio em todos os países. Sendo assim, pode-se concluir que o desenvolvimento e a proteção ambiental caminham juntos, não sendo possível analisá-los isoladamente, ambos constituem direitos humanos, do interesse comum da humanidade (Barros, 2008; Trindade, 1991).

Segundo Trindade (1993), os direitos humanos e as questões ambientais têm sido hoje, na maioria das abordagens, enfocados de forma globalizante, o que contribui para "acelerar as grandes transformações e o processo de humanização por que vem passando o direito internacional contemporâneo".

Ao questionamento: quando se viola o direito ao meio ambiente, também se viola direitos humanos? Até o presente momento isto não é uma consciência global, apesar de existirem tendências e proposições nesse sentido. A resposta será afirmativa quando o atendimento às necessidades humanas básicas, a redução da pobreza, das enfermidades, da discriminação e exclusão social, passarem a ser, necessariamente, uma responsabilidade conjunta do Estado e da sociedade.

Para se alcançar esses propósitos, novos paradigmas deverão ser construídos com fundamentos na ética, na consciência e educação ambiental, nos processos democráticos e participativos, no acesso às informações, a fim de se propor novas formas de viabilizar a construção de um mundo saudável e justo, onde efetivamente serão exercidos os direitos humanos ambientais. Isto dá testemunho da indivisibilidade dos direitos humanos ambientais: uma vez afirmado como um direito humano, o direito a um meio ambiente sadio, ao invés de acarretar restrições ao exercício de outros direitos, vem enriquecer o corpus dos direitos humanos consagrados (Dallari, 2005). 


\section{CONSIDERAÇÕES FINAIS}

O direito ao meio ambiente considerado ecologicamente equilibrado e sustentável é direito à dignidade da pessoa humana, integrando a denominada terceira geração dos direitos fundamentais, e a proteção do meio ambiental é dever do Estado e da coletividade, redundando em verdadeira solidariedade em torno de um bem comum. Assim, é assegurado pela Constituição como direito fundamental de terceira geração, diretamente relacionado com o direito à vida das presentes e futuras gerações.

A busca a se garantir um padrão mínimo de existência e proporcionar uma dignidade humana, das presentes e futuras gerações torna-se necessário perguntar-nos se o direito a um meio ambiente adequado e suficientemente importante para ser elevado a categoria de um direito humano, podemos tomar em conta o papel transcendental que desempenha o meio no desenvolvimento humano. Aquele direito é um dos pilares do reconhecimento de outros como o direito à vida e à saúde.

As correntes que fundamentam os direitos humanos revelam que estes são inerentes ao homem, que é necessário uma positivação para que se possa buscar a efetividade, mas também que os direitos humanos surgem de uma consciência social que faz a humanidade partilhar de valores comuns a partir da mudança de paradigmas.

Neste contexto, o meio ambiente como direito reconhecido no âmbito internacional e consagrado no direito pátrio postulado no art. 225 da Constituição Federal é compreendido como direito fundamental e, por via de conseqüência, também um dos Direitos Humanos relacionados diretamente à qualidade de vida do ser humano.

Dessa forma, logo se vislumbra o nexo entre Direitos Humanos e Meio Ambiente, posto que este último fosse previsto expressamente no texto constitucional cons- titui-se como direito fundamental e inerente a toda uma coletividade.

De maneira geral, a efetivação dos direitos humanos e o meio ambiente ainda é um processo em transição, que ressalta de forma exeqüível e incisiva no cenário jurídico, econômico, político e social no âmbito nacional e internacional. Nesse sentido, a proteção ao meio ambiente é essencial para a dignidade da pessoa humana, nos aspectos da melhoria de sua qualidade de vida, bem como preservação de sua incolumidade física e moral.

\section{REFERÊNCIAS BIBLIOGRÁFICAS}

ALEXY, R. Teoria de los derechos fundamentales. Madrid: Centro de Estúdios Constitucionales, 1997. 610p.

ALVES, J. A. L. Os direitos humanos como tema global. São Paulo: Perspectiva, 2003. 10 p.

BARROS, W. P. Curso de direito Ambiental. 2 ed. São Paulo:Atlas, 2008. 529 p.

BERTOLDI, M. R. O direito humano a um meio ambiente equilibrado. Disponível em <http://www1.jus.com.br/doutrina/texto. asp?id=1685>. Acesso em: 02 jul. 2010.

BOBBIO, N. A era dos direitos. Tradução de Carlos Nelson Coutinho. Rio de Janeiro: Campus, 1992. 219p.

BRASIL. Constituição da República Federativa do Brasil: promulgada em 5 de outubro de 1988. Obra coletiva de autoria da Editora Saraiva com a colaboração de Antônio Luiz de Toledo Pinto, Márcia Cristina Vaz dos Santos Windt e Lívia Céspedes. 29 ed. São Paulo: Saraiva. 2002.

CHAGAS, M. C. O Direito ao Meio Ambiente Como Direito Fundamental à Vida. 1998. 
175p. Dissertação (Mestrado em Direito Público) - Universidade Federal do Ceará, Fortaleza.

CAMPILONGO, C. F. Os desafios do judiciário: um enquadramento teórico. In: FARIA, José Eduardo (Org.). Direitos humanos, direitos sociais e justiça. SãoPaulo: Malheiros, 2002. 156p.

COMPARATO, F. K. A afirmação histórica dos Direitos Humanos. 2 ed., São Paulo: Saraiva, $2001.577 \mathrm{p}$.

CONCEIÇÃO, M. C. F. da. O papel das ONGs na defesa do meio ambiente: o exercício da cidadania. In: FREITAS, Vladimir Passos de et al. Direito ambiental em evolução. v. 3. Curitiba: Juruá, 2003. 398p.

DALLARI, D. de A. Estado de direito e direitos fundamentais. In: ALMEIDA FILHO, Agassiz de; CRUZ, Danielle da Rocha (Coord.). Estado de direito e direitos fundamentais: homenagem ao jurista Mário Moacyr Porto. Rio de Janeiro: Forense, 2005. p. 176.

DINIZ, M. H. Curso de Direito Civil Brasileiro. Teoria Geral do Direito Civil. v. 1. $26^{\mathrm{a}}$ ed. São Paulo: Saraiva, 2009. 636p.

FACIN, A. M.. Meio ambiente e direitos humanos . Jus Navigandi, Teresina, ano 7, n. 60, nov. 2002. Disponível em: <http://jus2. uol.com.br/doutrina/texto.asp?id=3463>. Acesso em: 03 jul. 2010.
MARUM, J. A. de O. Meio ambiente e direitos humanos. In: Revista de Direito Ambiental. Coord. Antônio Herman V. Benjamin e Édis Milaré, n. 28, out./dez., 2002. p. 119.

ORGANIZAÇÃO DAS AÇÕES UNIDAS. Carta da Organização das Nações Unidas. Disponível em <http://www.onu-brasil.org.br/doc1.php $>$. Acesso em: 02 jul. 2010 .

SARLET, I. W. O Princípio da Dignidade da Pessoa Humana e os Direitos Fundamentais. 2. ed. Porto Alegre: Livraria do Advogado, 2002. 170p.

SCHÄFER, J. Classificação dos direitos fundamentais: do sistema geracional ao sistema unitário: uma proposta de compreensão. Porto Alegre: Livraria do Advogado, 2005. p. 14.

TRINDADE, A. A. C. A proteção internacional dos direitos humanos. São Paulo: $\mathrm{Sa}-$ raiva. $1991.171 \mathrm{p}$.

Direitos humanos e meio ambiente: paralelo dos sistemas de proteção internacional. Porto Alegre: Sérgio Antônio Fabris Editor. 1993.544 p.

VENOSA, S. de S. Direito Civil - Parte Geral. v.1 10 ${ }^{\mathrm{a}}$ Ed. São Paulo: Ed. Atlas S. A., $2010.594 \mathrm{p}$. 